\section{Desafios Relacionados ao Fim da Vida Humana: Apontamentos Acerca da Bioética Clínica}

\section{Bastos, Fernanda da Silveira}

Psicóloga, Especialista em Paciente Crítico, Mestranda em Bioética pela Cátedra Unesco de Bioética, Universidade de Brasília.psifernandabastos@gmail.com

\section{Araújo, Tereza Cristina Cavalcanti Ferreira de}

Professora da Universidade de Brasília, Instituto de Psicologia, Programa de Pós-Graduação em Bioética, Brasília/DF, Brasil.

Palavras Chave: bioética clínica, terminalidade, eutanásia, distanásia, UTI.

Introdução: A medicina em seu processo de afirmação enquanto ciência se legitima como tal ao promover e desenvolver técnicas que partilham um objetivo específico; o prolongamento da vida. Com o avanço da medicina e dos hospitais, a morte deixa de ser um evento público e se torna algo distante e mesmo "sujo", que precisa passar despercebido, escondido e solitário em um leito de hospital. Mais especificamente as Unidades de Terapia Intensiva (UTI), revestidas com uma arquitetura específica, investidas com tecnologias duras e disponibilizando profissionais competentes e exigentes, se configuraram em um espaço quase hierárquico, por assim dizer, do nível mais alto de oferta de recursos humanos e tecnológicos para o cuidado do paciente crítico. $\mathrm{Na}$ maioria das vezes, são nesses espaços que se encontram muitos pacientes que enfrentam situações de terminalidade. Método: Trata-se de uma pesquisa de revisão da literatura, que buscou coletar produções nas seguintes bases de dados: Scielo e PubMed (2013 a 2018), selecionando-se como descritores: bioética (bioethics); tomada de decisões (decison making); autonomia (autonomy), em cruzamento com paciente terminal (terminal patient). Resultados: O princípio da autonomia aparece como uma porta entreaberta como uma possível saída ao dilema do respeito à vontade e ao direito de autogovernar-se em pacientes em condições terminais. Entretanto, é notório, que ainda há muita confusão entre os próprios profissionais de saúde sobre as definições de eutanásia ativa; eutanásia passiva/ortotanasia, e distanásia. É evidente na literatura que tanto em contexto internacional quanto nacional, bioeticistas clínicos que atuam em hospitais, especialmente em UTI, trazem contribuições na oferta de cuidados e na tomada de decisões, diante de um cenário, no qual não só os médicos, mas grande parte dos profissionais de saúde apresenta uma formação claudicante em relação ao tema da morte e do morrer. Ademais, algumas pesquisas apontam que esses profissionais lidam cotidianamente com situações limítrofes, nas quais muitas vezes exacerba-se um sentimento de impotência. Conclusões: $O$ nascimento da bioética está atrelado a questões marcantes e revolucionárias da ciência diante do processo do viver e do morrer, como os transplantes, as reproduções assistidas, as condições de manutenção artificial de vida, o suicídio assistido, entre outros. E, nesse sentido, os dilemas bioéticos sobre o fim da vida são inúmeros. As condições de vida impostas pela medicina moderna aos doentes terminais podem levar a gestos suicidas por parte desses doentes. O processo do morrer, mesmo em um hospital, não conota apenas sobre a morte de um corpo biológico, mas também, aponta para a finitude da concretude humana. Nesse sentido torna-se claro, a legitimidade de atuação da bioética clínica, esta, enquanto campo de saber e prática dispõe de inúmeros instrumentos que podem auxiliar as discussões e nortear as tomadas de decisões da equipe e favorecer a integralidade do cuidado ao paciente.

Agradecimentos: Agradecemos a CAPES (Coordenação de Aperfeiçoamento de Pessoal de Nível Superior) por possibilitar que esse trabalho fosse realizado.

\section{Referências:}

[1] CALLAHAN D. The Roots of Bioethics: Health, Progress, Technology, Death. Oxford University Press; 1. Ed., 2012.

[2] HORTA, MP. Eutanásia - problemas éticos da morte e do morrer . Bioética (CFM) 7(1)27- 33, 1999.

[3] MORITZ, R. e cols. Terminalidade e cuidados paliativos na unidade de terapia intensiva. Rev. bras. ter. intensiva vol.20 no.4 São Paulo Oct./Dec. 2008.

[4] PESSINI, L. Distanásia: até quando investir sem agredir. Bioética (CFM)4(1):31-43, 1996.

[5] KOVÁCS, M. J. Educação para a morte: temas e reflexões. $2^{a}$ ed. São Paulo: Casa do Psicólogo, 2012. 